TP Periodica Polytechnica

Mechanical Engineering

61(2), pp. 94-106, 2017

https://doi.org/10.3311/PPme.9345

Creative Commons Attribution (i)

RESEARCH ARTICLE

\section{Simulation and Experimental Investigation of the Stay Vane Channel Flow in a Reversible Pump Turbine at Off-Design Conditions}

\author{
Sandro Erne ${ }^{1 *}$, Gernot Edinger ${ }^{1}$, Anton Maly ${ }^{1}$, Christian Bauer ${ }^{1}$
}

Received 18 April 2016; accepted after revision 23 November 2016

\begin{abstract}
This work presents the assessment of the mean flow field and low frequency disturbances in the stay vane channel of a model pump turbine using transient numerical simulations and LDV-based measurements. The focus is laid on transient CFD simulations of characteristic flow states in the stay vane channel when operating at off-design conditions in pump mode. Experimental and numerical investigations obtained a shifting velocity distribution between the shroud and hub of the distributor when continuously increasing the discharge in the part-load range. Simulations captured the occurrence of this changing flow state in the stay vane channel reasonably well. A further increase of the discharge showed a uniformly redistributed mean flow of both hub and shroud side. Monitoring points and integral quantities from measurements and transient simulations were used to interpret the development of transient flow patterns in the stay vane channel at the operating point of strongest asymmetrical flow. During simulation and measurement, a dominant rotating stall inception was observed near the design flow of the pump turbine. At this point where the stall becomes severe, a high level of correlation between the signals of the upper and lower stalled flow in the stay vane channel was calculated. Further simulations for different guide vane positions predicted a strong influence of the guide vane position on the structure of rotating stall.
\end{abstract}

\section{Keywords}

transient simulations, OpenFOAM, pump turbine, rotating stall, stay vane channel, CFD, LDV

\section{Introduction}

Increasing the operational flexibility of a pumped storage power plant often involves an extension of the continuous operating range of the pump turbine. Also, large head variations are mostly associated with a wide off-design operating range. This makes it necessary to ensure off-design operating characteristics with low fluid dynamical effects at a high degree of reliability. Especially during pump mode, part-load flow conditions can cause periodically unsteady flow patterns in the distributor section of the pump turbine. The occurrence of such unsteady flow phenomena upstream of the runner like stalling flow or Rotor-Stator-Interaction were investigated by many authors in the past.

Mesquita and Ciocan [1] are one of the few authors, who studied the flow in the stay vane channel of a pump turbine focusing on the flow between guide vanes and stay vanes.

A very slow rotating stall in the diffuser channel rotating at $1 \%$ of the impeller rotational speed was observed in [2] by performing experimental analysis with a centrifugal pump $\left(n_{q}=21 \mathrm{rpm}\right)$ at $Q / Q_{n}=0.8$. Similar observations at a flow rate $Q / Q_{n}=0.8$ are reported in [3] and also [4, 5] who revealed the onset of rotating stall phenomena. Furthermore, at a partload flow rate $Q / Q_{n}=0.77$, Zhang [6] detected by means of instationary LDV-measurements a significant frequency peak at $1-2 \mathrm{~Hz}$, induced by periodically unsteady flow.

In this work, several off-design operating points are analyzed to get information on the flow behavior in the stay vane channel, including zero-flow and full-load conditions. Measurements of a model pump turbine are used to assess the capability of the simulations to predict transient flow mechanisms. LDV technique is applied to the model pump turbine which provides optical accessibility in the spiral case.

A detailed analysis of several quantities at operating point $Q / Q_{n}=0.74$ allows a better understanding of the substantially altering flow patterns close to the stay vane channel. This also makes it possible to draw conclusions about the influence of stalled flow on the global flow behavior in the distributor.

The following work is based on the paper submitted at the CMFF15 [7]. 


\section{Experimental setup}

Experiments were carried out on a reduced scale model machine which was set up on a test rig (see Fig. 1), allowing model testing according to the IEC 60193 standard. The discharge can be set independent from guide vane setting by means of a needle valve located in the high pressure piping. For prototype homologous investigations at zero discharge a ball valve (DN 300) is installed directly upstream of the spiral case. The control of the test rig and the data acquisition for the global performance data was implemented in LabVIEW. In Fig. 2, the model pump turbine during measurements is shown. For the measurement of the velocity components $C_{m}$ and $C_{z}$ in the stay vane channel a 2D LDV system in back-scatter mode was used. The 2D LDV system consists of a Argon-Ion-Laser. The $514.5 \mathrm{~nm}$ beams were used for measuring the $C_{m}$ component and the $488 \mathrm{~nm}$ beams were used for determining the $C_{z}$ component of the velocity. Two acrylic windows installed in the spiral casing provide optical access to the flow region of interest. The surfaces of the acrylic windows were machined plane-parallel for easier positioning of the LDV laser beam intersections. Figure 3 shows the LDV beams for the two different velocity components when looking through one of the two windows in the spiral case. After performing some tests with polycarbonate seedings, the experiments were carried out using very small air bubbles as seeding particles which are a convenient alternative. The intersection of the beams were positioned at the defined monitoring points using a 2-axis traverse system controlled by the LDV data acquisition software DataVIEW 1.10. Instationary pressure measurements of $p_{\text {prim }}$ were performed using an absolute pressure transducer installed in the vaneless space between runner and guide vanes (priming chamber) at the bottom ring. The static pressure in the draft tube cone was measured by means of four piezoresitive pressure transducers. The software LabVIEW has been used for signal processing and data acquisition.

More details and information about the experimental setup and employed measurement techniques can be found in [8]. The main data of the scale-model pump turbine are given in Table 1.

Table 1 Design parameters of the model pump turbine.

\begin{tabular}{lcll}
\hline specific speed & $n_{q}$ & 41.5 & $\mathrm{rpm}$ \\
inlet diameter & $D_{1}$ & 0.276 & $\mathrm{~m}$ \\
impeller speed & $n$ & 800 & $\mathrm{rpm}$ \\
number of blades & $z_{b}$ & 7 & - \\
number of guide vanes & $z_{g}$ & 20 & - \\
number of stay vanes & $z_{s}$ & 20 & - \\
\hline
\end{tabular}

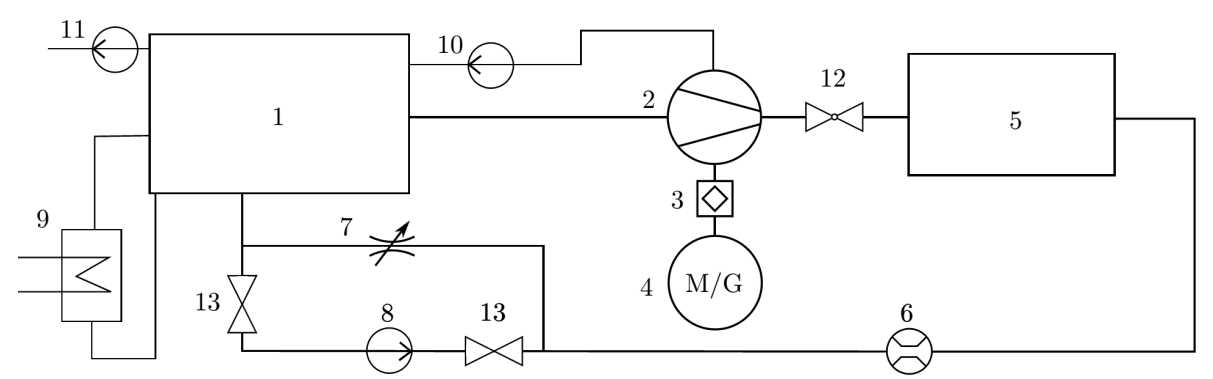

Fig. 1 Scheme closed circuit: 1 tailwater vessel, 2 reduced scale model, 3 hydrostatic bearing, 4 motor-generator, 5 headwater vessel, 6 flow meter, 7 needle valve, 8 pump, 9 cooling system, 10 sealing-water system, 11 vacuum pump, 12 ball valve, 13 butterfly valve.

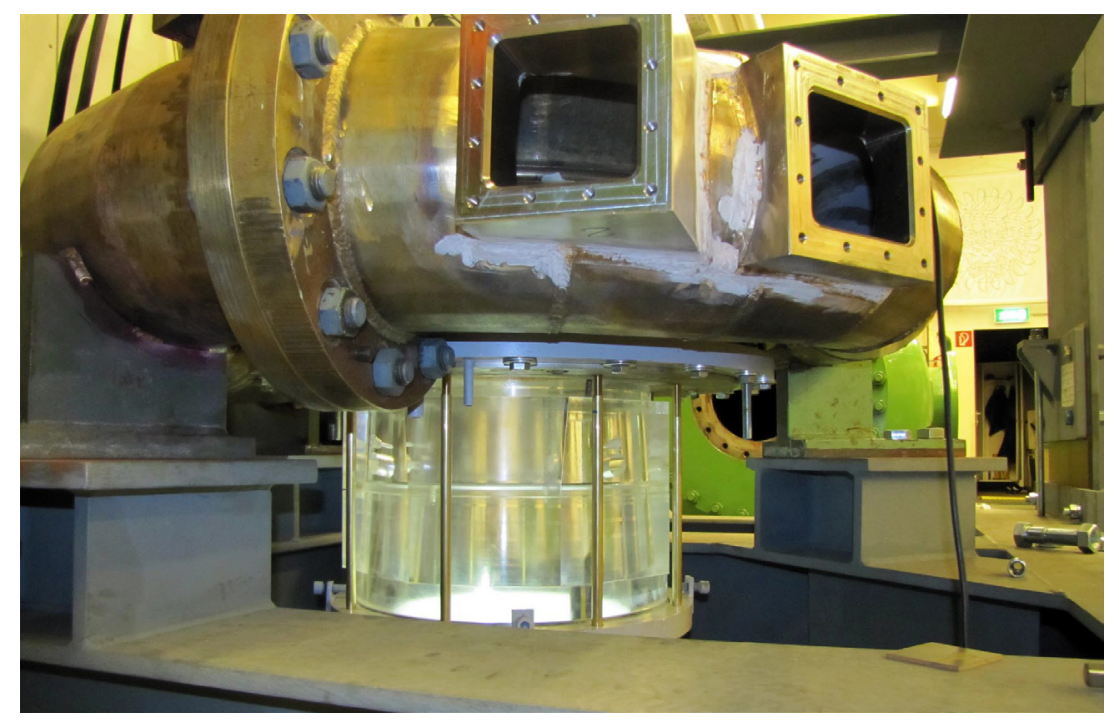

Fig. 2 Spiral case of turbine test rig with optical access windows and acrylic draft tube cone. 


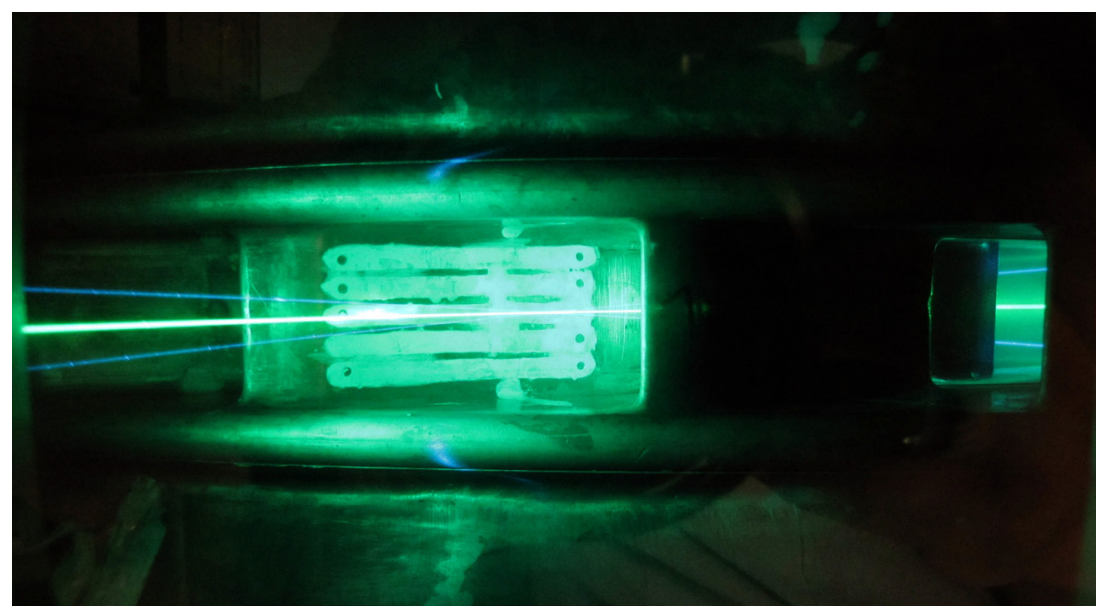

Fig. 3 Spiral case section with stay vanes during LDV measurements.

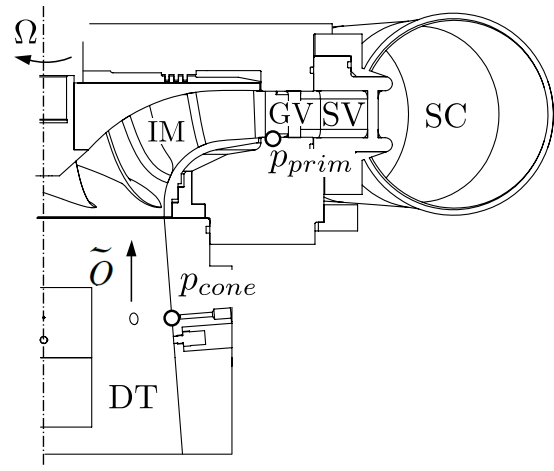

Fig. 4 Configuration of the computational domain: DT draft tube, IM impeller (rotating domain), GV guide vanes, SV stay vanes, $\mathrm{SC}$ spiral case, $\left(^{\circ}\right)$ wall pressure taps.

\section{Numerical method}

\subsection{Computational set up}

The open-source CFD software OpenFOAM was used to solve the unsteady flow governed by the incompressible Reynolds-averaged Navier-Stokes equations. To ensure high grid quality and specific mesh refinement regions, the computational grids have been created with the meshing tool ICEM $^{\mathrm{TM}}$ [9]. A limited 2nd-order scheme was applied for the convection and diffusion terms which is described in Section 3.3. As schematically illustrated in Fig. 4, the mesh consists of the subdomains draft tube, impeller, guide vane, stay vane and spiral case. Figure 5 shows the computational domain with the rotating and stationary grid zones that are connected via interfaces.

The number of cells was reduced to a minimum to avoid unnecessary computation time, although taking into account sufficient grid resolution in regions of interest. Hence, the grid has only $N=2.5 \times 10^{6}$ cells in total. Relevant mesh properties can be found in Table 2 for each sub-domain.

The stay vane passage has a mesh resolution of $N_{\theta}=27$ in pitchwise direction, $N_{z}=26$ in spanwise direction and $N_{m}=$ 30 in streamwise direction. The multidomain mesh consists of the sub-domains inlet cone, runner, guide vane and stay vane

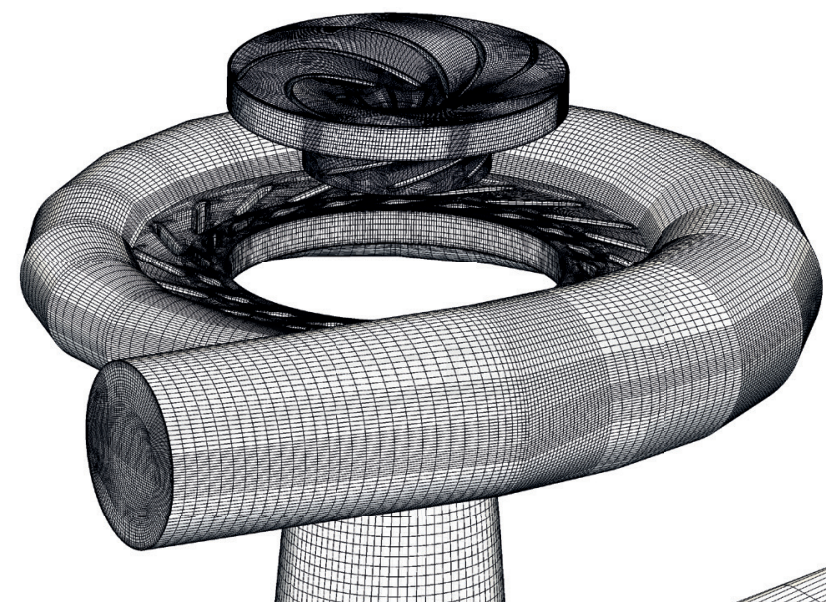

Fig. 5 Overview of the computational grid.

which are of different mesh type. A H-O type meshing technique was used for internal flow domains like guide vanes and stay vanes, as shown in Fig. 6. For the spiral case and the draft tube, an O-grid type multiblock structure was applied. As the grid is of pure block-structure type, the grids include hexahedral cell structures only and allow the usage of wall functions.

Table 2 Mesh statistics.

\begin{tabular}{llll}
\hline mesh sub-domain & type & $\mathrm{N}$ & $y^{+}$ \\
draft tube DT & stationary & $102^{\prime} 960$ & 19.1 \\
impeller IM & rotating & $543^{\prime} 522$ & 35.7 \\
stay vane SV & stationary & $367^{\prime} 394$ & 29.2 \\
guide vane GV & stationary & $626^{\prime} 280$ & 58.2 \\
spiral case SC & stationary & $857^{\prime} 593$ & 69.1 \\
\hline
\end{tabular}

The $k$ - $\omega$ SST turbulence model with automatic wall treatment was applied for all simulations performed which is well suited for ducted flows with adverse pressure gradients. This standard wall treatment accounts for improper meshing of the boundary layer and provides a better near-wall behavior of the turbulent quantities. The first cell center off solid surfaces was 


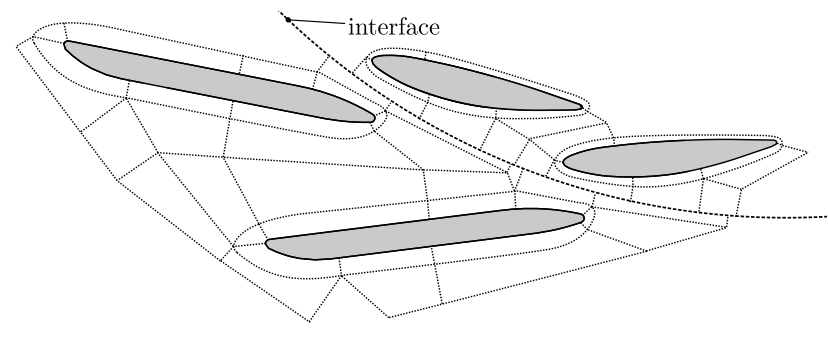

Fig. 6 Periodic block structure of the distributor section.

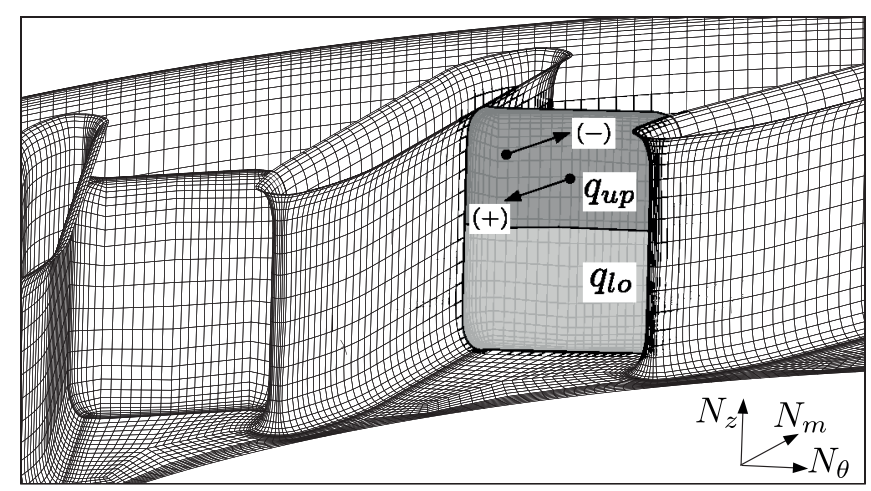

Fig. 7 Grid spacing $\left(N_{m} \times N_{\theta} \times N_{z}\right)$ of domain SV and sampling zones: $q_{u p}$ flow rate upper channel zone, $q_{l o}$ flow rate lower channel zone; radial inward $(+)$, outward $(-)$.

defined to achieve an average cell-centered $y^{+}>12$. At the fluid domain inlet, profiles for the velocity and the turbulent quantities were defined. The cross section in the stay vane passage was divided into an upper and lower channel zone to assess the flow structure separately, as illustrated in Fig. 7. A time step of $\Delta t=1^{\circ}$ of impeller rotation was prescribed to properly capture the wake region of the impeller blades that affects the guide vane flow. In order to achieve a quasi steady-state flow in the stay vane channel, at least 10 runner revolutions were simulated for each operating point. All quantities of interest were sampled over time for approximately 30 runner revolutions.

The guide vane setting $\alpha_{o} / \alpha_{o n}$ is 0.67 for all following simulations where $\alpha_{\text {on }}$ corresponds to the opening at the global best efficiency point $\left(Q / Q_{n}=1\right)$. When operating at $Q / Q_{n}=0.74$, however, the best efficiency is obtained at $\alpha_{o}$.

As OpenFOAM enables fully parallelized computing using the MPI standard, parallel simulations were run on up to 32 cores.

\subsection{Grid Independence Study}

Two grids $G_{i}$ of different refinement with $N_{i}$ cells were used for simulations to obtain the respective solutions $f_{i}$. Discretization schemes are of order $p_{i}$ in both space and time. A reference solution from experiments $f_{E X P}$ is introduced so that only solutions obtained from two successively refined meshes are necessary to show mesh independence. For this study, the grid refinement ratio $r=\left(N_{2} / N_{1}\right)^{1 / 3}$ between respective meshes is $r=h_{1} / h_{2}=\sqrt{2}$, where $h$ denotes the grid spacing.

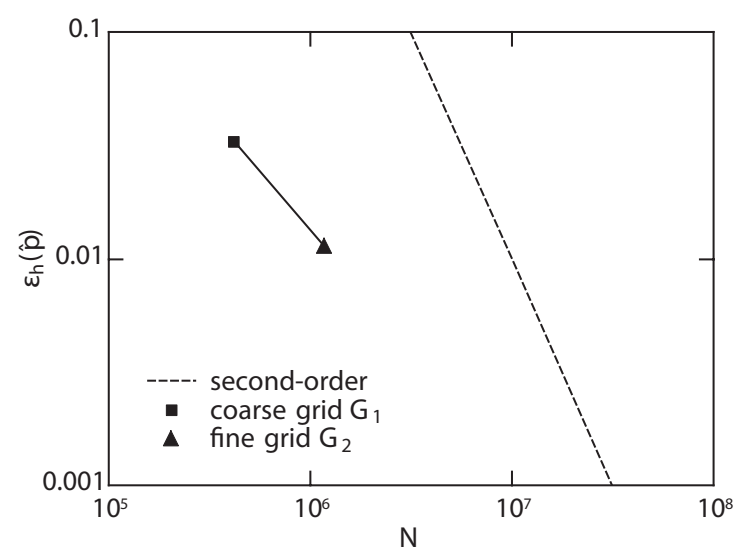

Fig. 8 Discretization error.

The chosen refinement ratio complies with the suggested lower limit $r>1.3$ from [10]. The measured static pressure difference between the monitor point in the draft tube cone $p_{\text {cone }}$ and the monitor point in the priming chamber $p_{\text {prim }}$ was used for the reference solution $f_{E X P}$. The normalized solution from the simulation has the form

$$
f=\frac{8\left|p_{\text {prim }}-p_{\text {cone }}\right|}{\rho D_{1}^{2} \Omega^{2}}
$$

where $D_{1}$ denotes the runner inlet diameter and $\Omega$ the impeller angular speed. The observed order of accuracy is expressed on the basis of the simulation results following

$$
\hat{p}=\frac{\ln \left(\left|\frac{f_{E X P}-f_{i+1}}{f_{i+1}-f_{i}}\right|\right)}{\ln (r)}=1.9 \quad i=1 \ldots 2
$$

By using the relationship [11]

$$
\varepsilon_{h, i}(p)=\frac{\left|f_{E X P}-f_{i}\right|}{r^{\hat{p}}-1}
$$

the discretization error of the grid $G_{i}$ is calculated. Details of the grid study can be found in Table 3. The error estimator in Fig. 8 shows that nearly 2 nd-order accuracy can be achieved when applying a $r$-refinement to the mesh. A grid spacing according to size $h_{2}$, see detail plot in Fig. 7, was used for all further simulations, since $\hat{p}$ of grid $G_{2}$ is close to second-order accuracy.

Table 3 Details of grid study.

\begin{tabular}{llll}
\hline grid & $N$ & $\operatorname{det}_{\text {min }}$ & $\varepsilon_{h, i}(\hat{p})$ \\
\hline$G_{1}$ & $422 ' 244$ & 0.31 & 0.033 \\
$G_{2}$ & 1'220'102 & 0.22 & 0.011 \\
\hline
\end{tabular}




\subsection{Discretization Order}

The convective fluxes were discretized with a flux-blending scheme, which proves generally to be more robust than a discretization scheme of 2nd-order accuracy. This blended high resolution TVD (Total Variation Diminishing) scheme was applied to the velocity and to the turbulence quantities, using a flux limiter $\psi(r)$ :

$$
\phi^{h r s}=\phi^{l}+\psi(r)\left(\phi^{h}-\phi^{l}\right) .
$$

The flux limiter is defined by

$$
\psi(r)=\max \left(\min \left(\frac{2}{k} r, 1.0\right), 0.0\right)
$$

Thus, for second-order accuracy, Eq. (5) yields $\psi(r)=1$ (central differencing). By contrast, an upwind differencing scheme of first order corresponds to $\psi(r)=0$. In Eq. (5), a user defined blending factor $k$ is introduced which satisfies the criteria $0 \leq k \leq 1$. The limiter function is based on a smoothness parameter $r$ which addresses the flux gradients between the computational cells. Details can be found in [12]. As $k<0.5$ was chosen for all fields, the order of accuracy $p_{i}$ may vary. With the relationship

$$
p_{i}^{h r s}=p_{i}^{l}+\overline{\bar{\psi}}_{i}\left(p_{i}^{h}-p_{i}^{l}\right) \quad i=1 \ldots 2
$$

the formal order of accuracy on grid $G_{i}$ is obtained, wherein $p_{i}^{l}=1.0$ and $p_{i}^{h}=2.0$. The blending factor $\overline{\bar{\psi}}$ is averaged over all faces of the computational domain and the computation time as well:
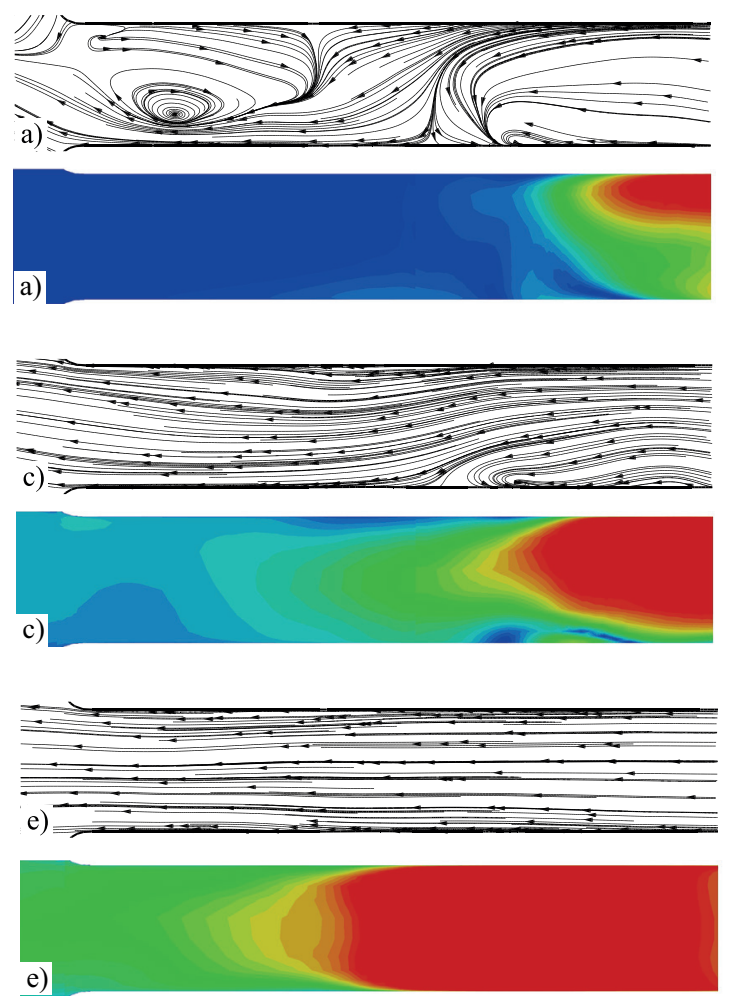

$$
\overline{\bar{\psi}}=\frac{\sum_{j=0}^{J} \Phi_{j} \psi_{j}}{\sum_{j=0}^{J} \Phi_{j}}
$$

In Eq. (7), the face flux is denoted by $\Phi$ and $J$ is the total number of faces in the computational domain. With Eq. (6) and Eq. (7) the order of convergence $p_{1}^{\text {hrs }}=1.86$ (coarse grid) and $p_{2}^{\text {hrs }}=1.90$ (fine grid) can be calculated. For $G_{1}$, the observed order of accuracy is slightly greater than the formal order of accuracy, which might be an indicator for non-asymptotic behavior.

\section{Results}

\subsection{Stay vane channel flow patterns}

Figure 9 shows contours of the averaged meridional velocity and according stream-lines in the region between runner outlet and spiral case inlet. The averaged meridional velocity is normalized by the circumferential velocity $u_{1}=\Omega D_{1} / 2$. As can be seen from Fig. 9(a), no significant net flow enters the spiral case during zero-discharge, but leads to separating flow in the stay vane passage due to high circumferential momentum from the runner outlet. When operating at $Q_{E D} / Q_{E D n}=0.21$ (Fig. 9(b)) or $Q_{E D} / Q_{E D n}=0.42$ (Fig. 9(c)) the flow enters the guide vane section mainly in the upper channel height, possibly due to prerotation at the runner inlet, and gets redistributed throughout the channel height again. At $Q_{E D} / Q_{E D n}=0.74$ (Fig. 9(d)), a more less uniform distribution of the mean meridional velocity in the guide vane section is
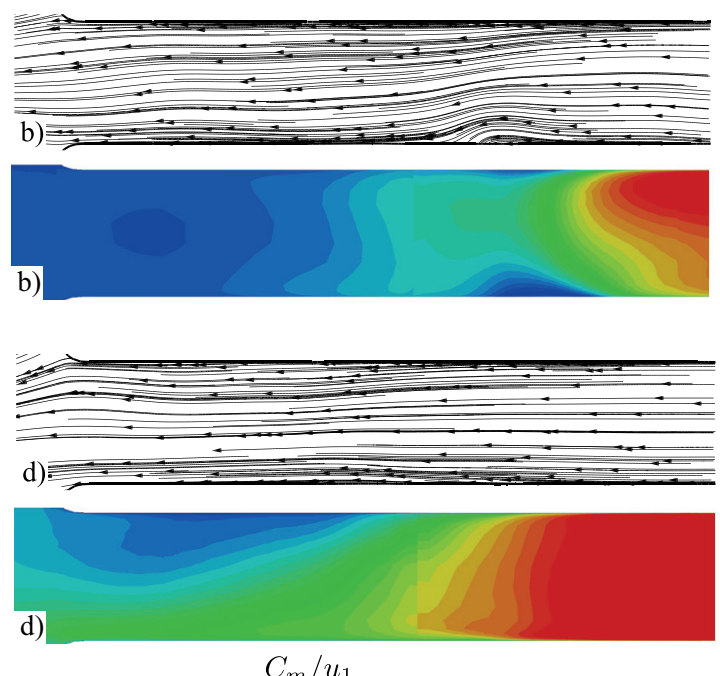

$C_{m} / u_{1}$

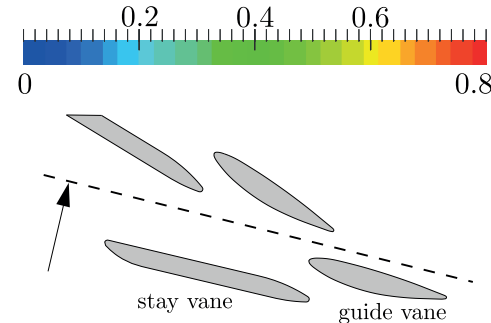

Fig. 9 Contour plots and streamlines of the time-averaged meridional velocity $C_{m}$ in the stay vane channel: a) $Q_{E D} / Q_{E D n}=0.0$, b) 0.21 , c) 0.42 , d) 0.74 , e) 1.33 . 

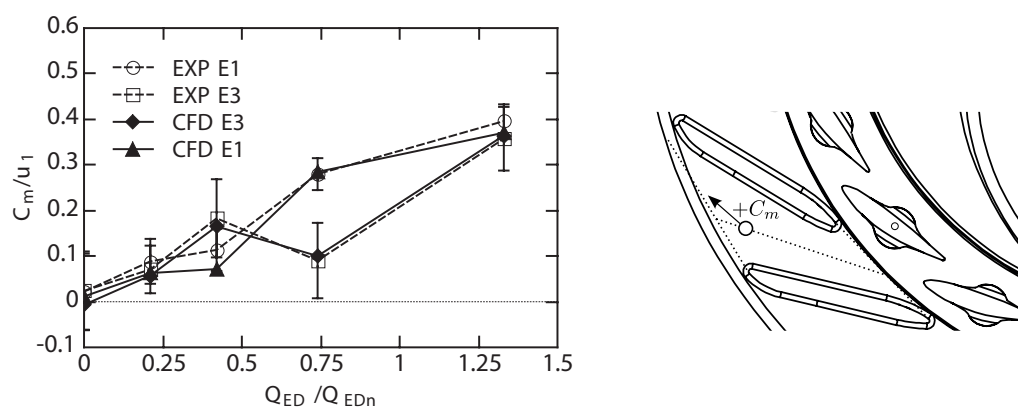

Fig. 10 Normalized meridional velocity component $C_{m}$ in the stay vane channel.
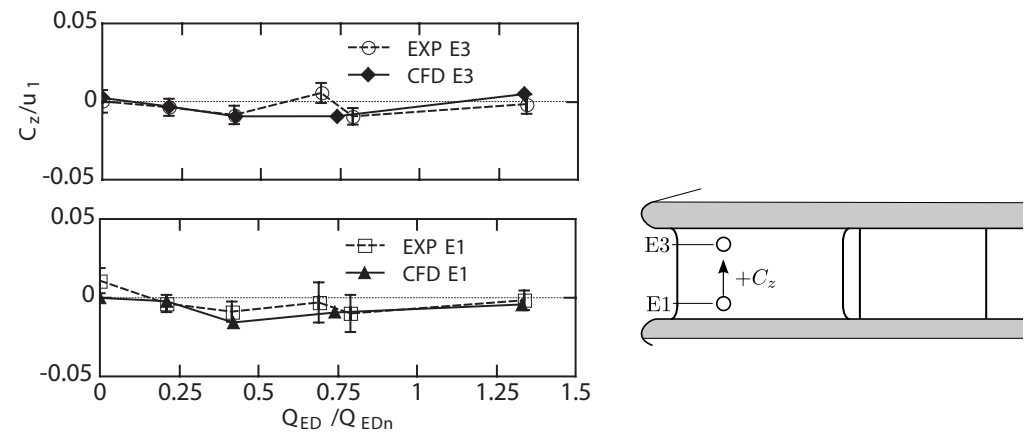

Fig. 11 Normalized spanwise velocity component $C_{z}$ in the stay vane channel.

shown, whereas in the inter-stay vane region downward flow is observed. At full load conditions $Q_{E D} / Q_{E D n}=1.33$, a uniform flow in meridional direction throughout the stay vane and guide vane channel is predicted, as can be seen from Fig. 9(e).

Velocity components $C_{m}$ and $C_{z}$ of the guide vane flow were analyzed at $25 \%$ (E1) and $75 \%$ (E3) of the distributor height, each at $50 \%$ in pitchwise direction. In streamwise direction, the two sampling points were located near the channel outlet at $90 \%$ of the stay vane length. Mean values of the velocity components $C_{m}$ and $C_{z}$ at the outlet of the stay vane passage near the shroud (E1) and hub (E3) are given in Fig. 10 and Fig. 11. The solid symbols refer to the simulation results. At zero discharge, the simulation revealed minor reversal flow in the stay vane channel what was not observed by flow velocity measurements, as can be seen in Fig. 10. However, it should be noted that the increased standard deviation (bars in Fig. 10) indicate strong velocity fluctuations. Compared to the lower sampling point E1, a higher velocity is obtained at sampling point E3 when increasing the discharge to $Q_{E D} / Q_{E D n}=0.42$. The diagram also shows that this asymmetry obtained from the simulation results remains somewhat too high for this operating point. Below the best efficiency point at $Q_{E D} / Q_{E D n}=0.74$, the higher velocity shifts from the upper sampling position E3 to the lower sampling position E1. Now, the uneven flow reaches its maximum and leads to high velocity rates in the lower stay vane channel region. Under full-load conditions, the flow redistributes to a symmetric velocity profile across the chann height, which also becomes abundantly clear from Fig. 9(e).

As can be seen from Fig. 11, the vertical velocity component from simulations show a proper agreement with experiments.
The slight downward flow in both sampling positions E1 and E3 is captured by simulation and experiments.

The development of the mean velocity along cross-sectional planes down-stream the stay vane passage is shown in Fig. 12. During part-load conditions $Q_{E D} / Q_{E D n}=0.21$ and 0.42 , the flow accumulates on the pressure side (PS) of the stay vane due to a low energy wake on the suction side (SS). Figure 12(d) shows a high asymmetrical flow behavior at operating point $Q_{E D} / Q_{E D n}=0.74$ which increases towards the downstream section of the stay vane channel. As in Fig. 12(e), the nearly uniform flow at the inlet of the stay vane passage gets decelerated and remains attached to the pressure side. Figure 13 visualizes vortical flow in the guide vane and stay vane passage by means of the Q-criterion. Zero-discharge operation (see Fig. 13(a)) shows strong vortices in the vaneless space between impeller and guide vanes. Fig. 13(c) and Fig. 13(d) show vortex shedding from the guide vanes. Especially at operating point $Q_{E D} / Q_{E D n}=0.74$, the Q-criterion reveals a high accelerated jet flow around the guide vanes as shown in the contour plot. As a result, the flow field around the stay vane is affected by strong flow separation where attached flow or fully blocked flow can be observed. When operating at full load conditions, too high incidence at the guide vane leading edge leads to strong flow separation at the pressure side of the guide vane. Figure 13(e) shows the shed vortices from the flow separation are moving farther downstream into the stay vane passage.

Time curves of both upper and lower flow rates are shown in Fig. 14 for over 20 runner revolutions. As in Fig. 14(b), moderate fluctuations are predicted for the upper and lower channel during deep part-load operation. The flow rate $q_{u p}$ through 
a)

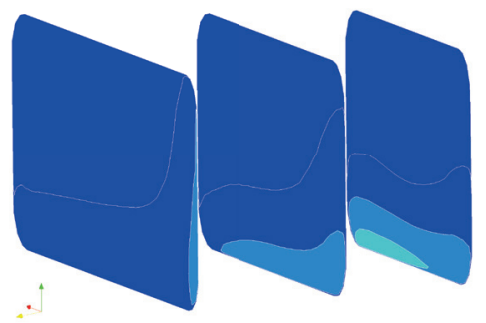

c)

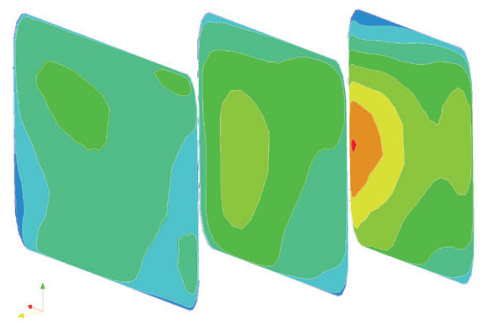

e)

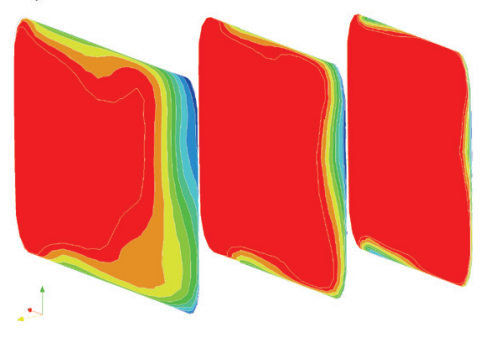

b)

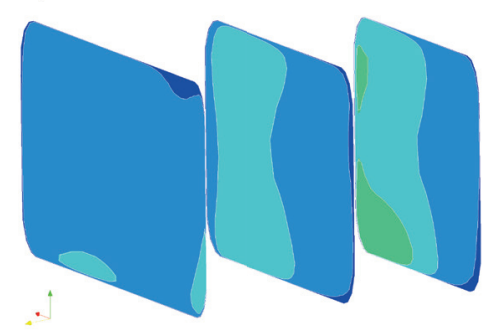

d)

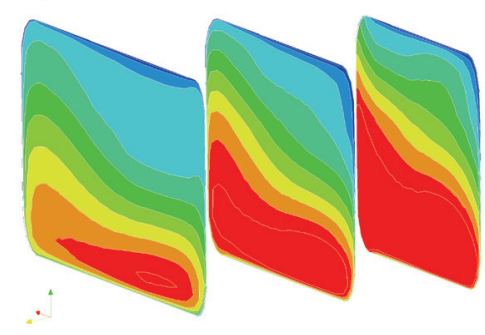

$\therefore$

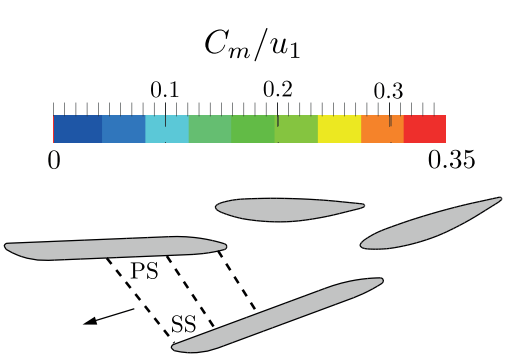

Fig. 12 Streamwise time-averaged velocity $C_{m}$ at various sampling planes in the stay vane passage: a) $Q_{E D} / Q_{E D n}=0.0$, b) 0.21, c) 0.42 , d) 0.74 , e) 1.33 (different scales).

the upper sampling plane of the stay vane passage is somewhat smaller than the flow rate $q_{l o}$ in the lower channel region. When comparing mean velocities extracted from these time histories with the meridional velocities from Fig. 10 the velocities might not match for some operating points, like $Q_{E D} / Q_{E D n}=0.42$. This is because the flow quantities $q_{u p}$ and $q_{l o}$ are based on numerical integration where the local velocity components $C_{m}$ are locally measured only.

The shape of the curve of both lower and upper flow rate in Fig. 14 is significant for operating point $Q_{E D} / Q_{E D n}=0.74$. The simulation shows a periodically appearing jet flow and blocked flow in both upper and lower channel region. This means that full-span blocked cells are formed periodically and drop the mass flow through these stay vane cells drastically.

At $Q_{E D} / Q_{E D n}=0.42$, no noticeable flow structure is observed but shows an increased net flow near the back shroud. When increasing the discharge to $Q_{E D} / Q_{E D n}=1.33$, flow rates remain fairly constant over the time.

Figure 15 presents the power spectra of the stay vane channel flow for various operating points where the amplitudes are normalized by the maximum amplitude calculated. From the waterfall plot, periodic disturbances at $Q_{E D} / Q_{E D n}=0.74$ are evident. Interestingly, the spectrum for $Q_{E D} / Q_{E D n}=0.21$ shows a remarkable similarity to this operating point in the low frequency region, at least for the upper flow $q_{u p}$.

Based on the time curves, the cross-correlation $R_{q_{l o} q_{u p}}$ between the upper and lower flow was performed for all guide vane openings on the basis of 30 runner revolutions, as illustrated in Fig. 16. A significant correlation is predicted when time periodic flow is present, as $R_{q_{l o} q_{u p}}=0.75$ for $Q_{E D} / Q_{E D n}=0.21$ respectively $R_{q_{l o} q_{u p}}=0.8$ for $Q_{E D} / Q_{E D n}=0.74$.

Based on these findings, a study of operating point $Q_{E D} / Q_{E D n}=0.74$ is presented in order to assess the dominant flow pattern in more detail.

\subsection{Stay vane channel flow at $Q_{E D} / Q_{E D n}=0.74$}

In order to provide accurate estimates of the flow structure also in the low-frequency range 40 impeller revolutions were simulated. Flow analysis were carried out for three different guide vane openings $0.8 \alpha_{o}, \alpha_{o}$ and $1.1 \alpha_{o}$ where $\alpha_{o}$ stands for the guide vane opening angle at which the best efficiency is obtained for this flow rate.

In Fig. 17, a Fourier transform was performed for both experimental and simulated static pressure signal $p_{\text {prim }}$ in the 

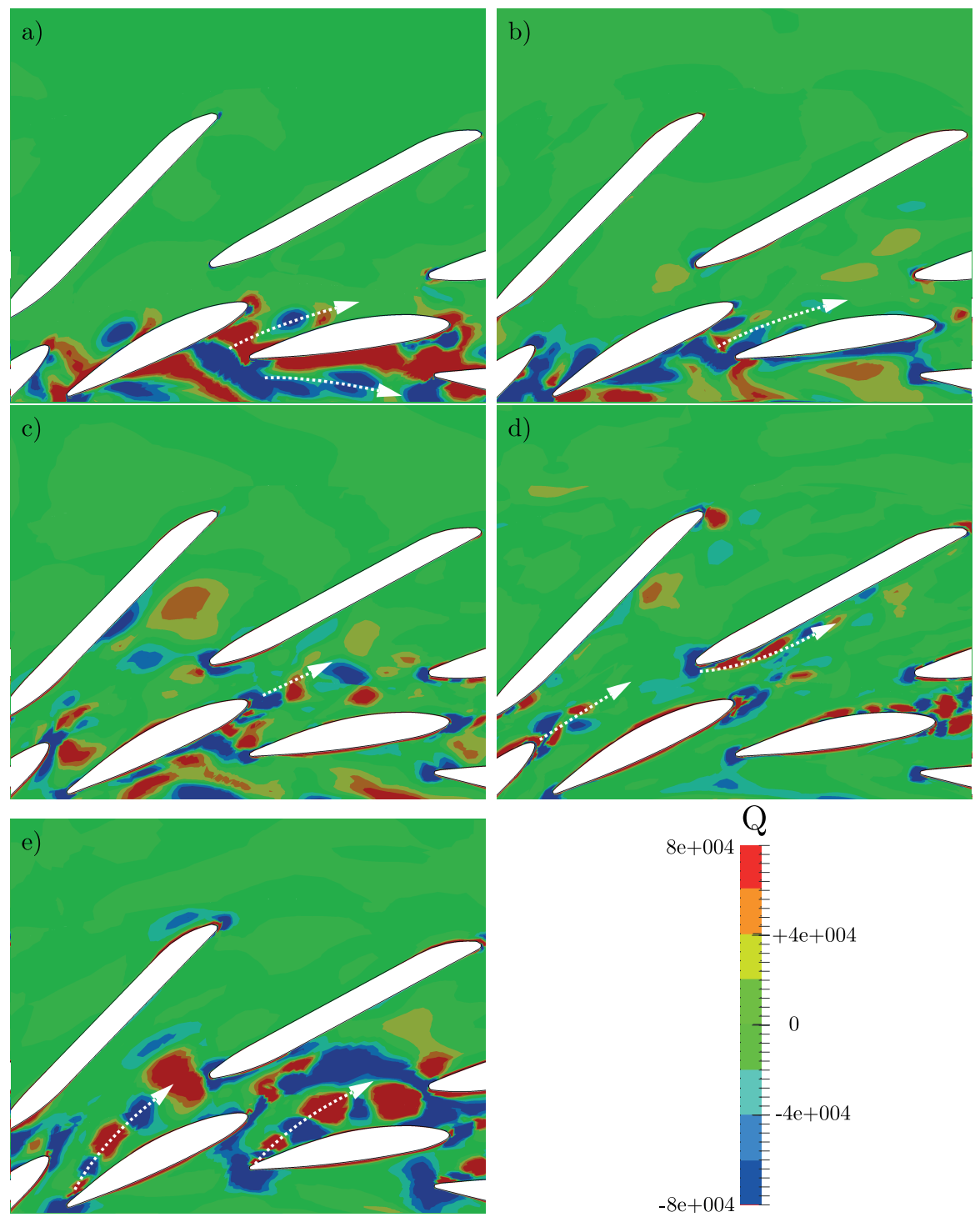

Fig. 13 Contour plot of the Q-criterion [13] (magnitude): a) $Q_{E D} / Q_{E D n}=0.0$, b) 0.21 , c) 0.42 , d) 0.74 , e) 1.33 .
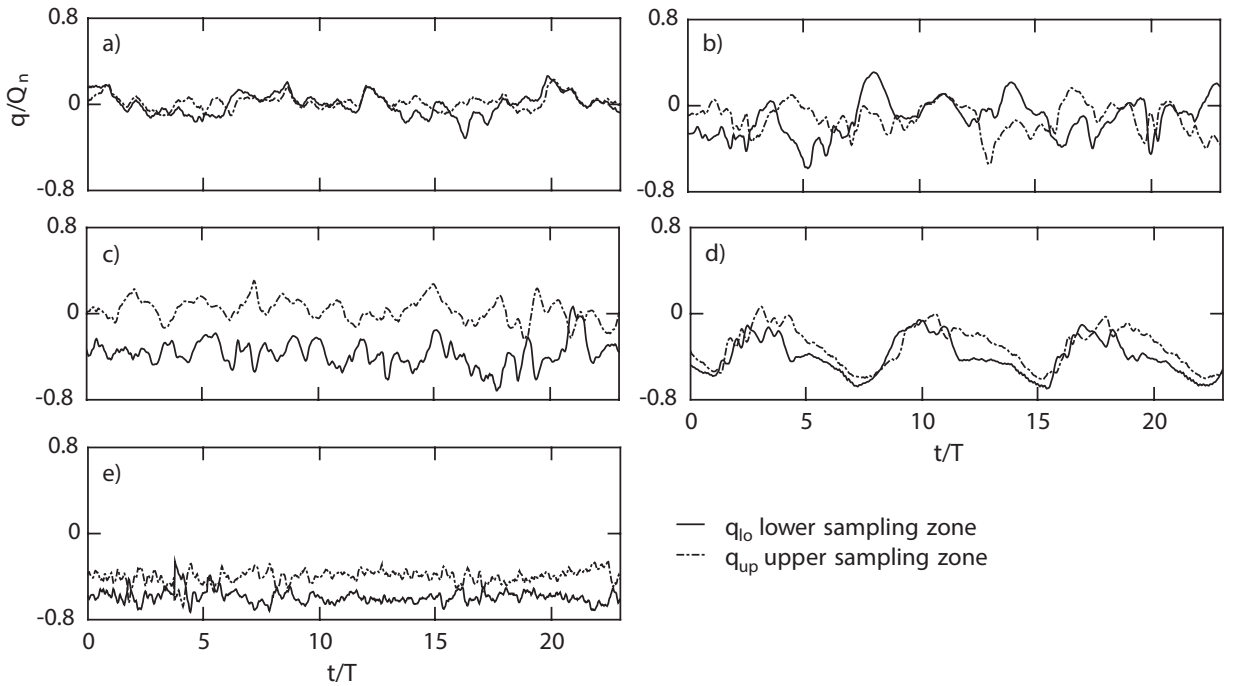

- $\mathrm{q}_{\mathrm{lo}}$ lower sampling zone

--- $\mathrm{q}_{\text {up }}$ upper sampling zone

Fig. 14 Normalized flow in the stay vane channels: a) $Q_{E D} / Q_{E D n}=0.0$, b) 0.21 , c) 0.42 , d) 0.74 , e) 1.33 . 


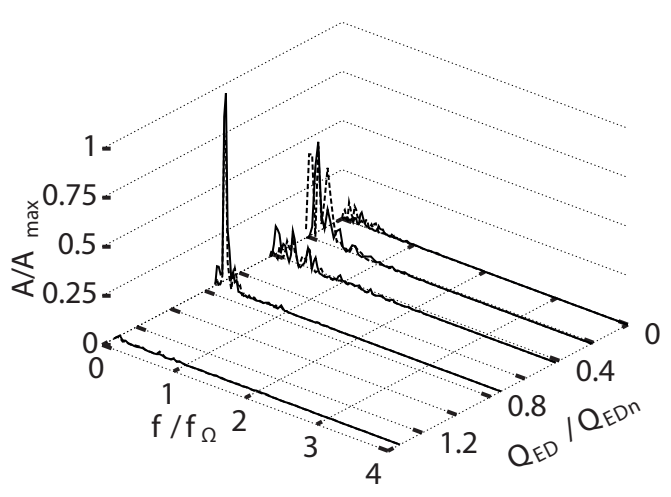

Fig. 15 Waterfall plot of power spectra of the stay vane channel flow $q_{u p}$ (solid line) and $q_{l o}($ dashed line).
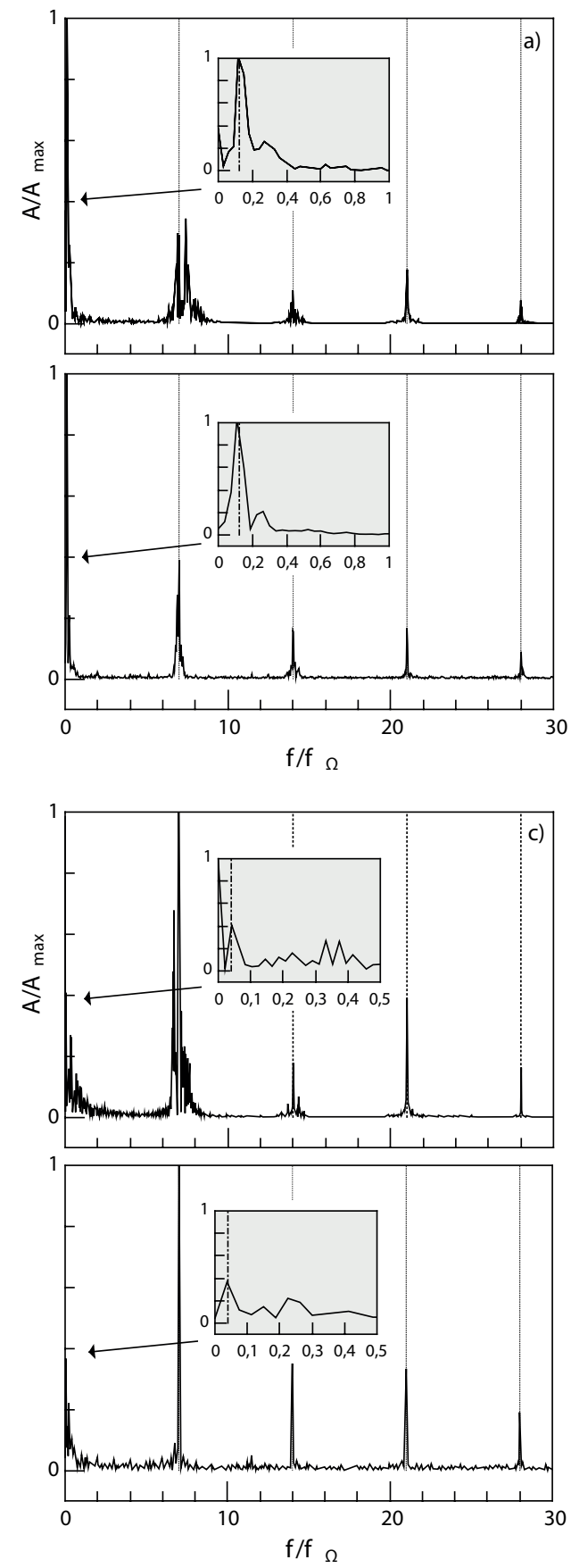

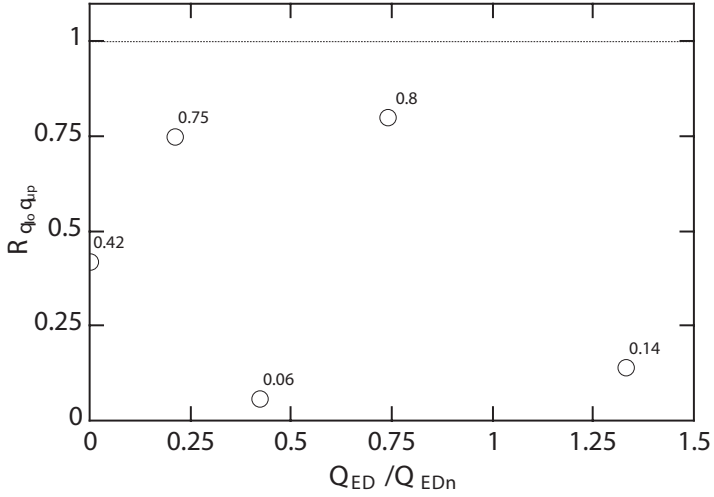

Fig. 16 Cross-correlation between upper and lower flow signal $R_{q_{l o} q_{u p}}=\sum_{i=1}^{n}\left(q_{u p, i}-\bar{q}_{u p}\right)\left(q_{l o, i}-\bar{q}_{l o}\right) / \sqrt{\sum_{i=1}^{n}\left(q_{u p, i}-\bar{q}_{u p}\right)^{2} \sum_{i=1}^{n}\left(q_{l o, i}-\bar{q}_{l o}\right)^{2}}$.
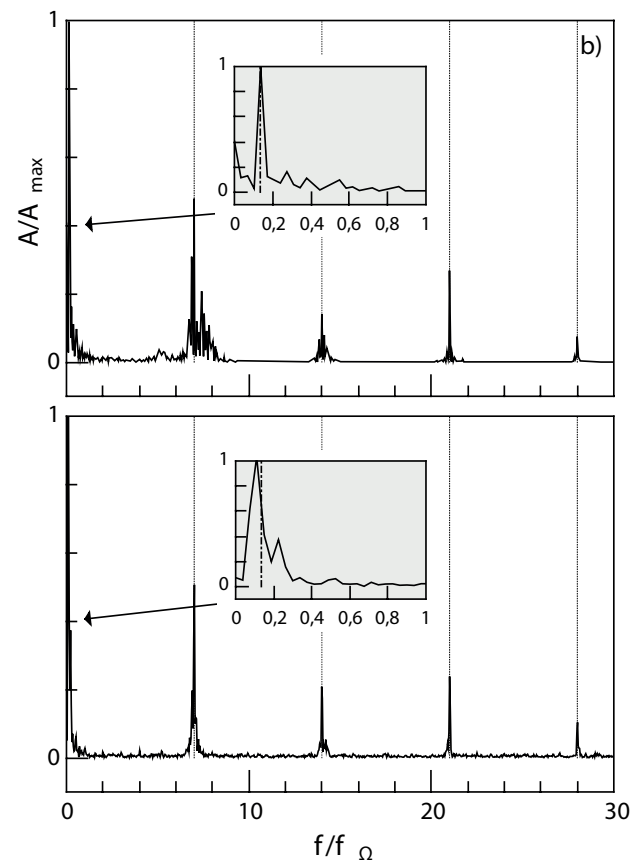

Fig. 17 Frequency spectra of the pressure signal $p_{\text {prim }}$ at $Q_{E D} / Q_{E D n}=0.74:$ a) $1.1 \alpha_{o}$, b) $\alpha_{o}$, c) $0.8 \alpha_{o} /$ CFD (top), EXP (bottom). 

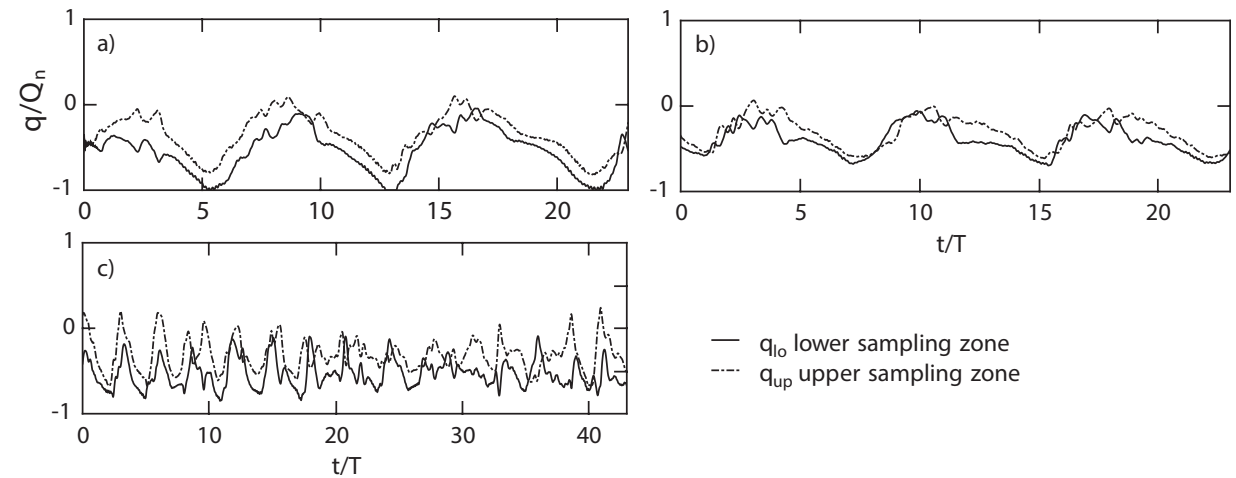

- $\mathrm{q}_{\mathrm{lo}}$ lower sampling zone

$---\mathrm{q}_{\text {up }}$ upper sampling zone

Fig. 18 Normalized flow in the stay vane channels at $Q_{E D} / Q_{E D n}=0.74:$ a) $1.1 \alpha_{o}$, b) $\alpha_{o}$ and c) $0.8 \alpha_{o}$ (different time scales).

vaneless space. The frequency is normalized by the impeller rotation frequency $f_{\Omega}$ where the fundamental impeller blade passing frequency and its harmonics are $i z_{b} f_{\Omega}$.

At large guide vane openings $\alpha_{o}$ and $1.1 \alpha_{o}$, the onset of rotating stall radically changes the flow in the distributor and leads to deep stall cells and high flow cells in the stay vane passage. For these openings, a dominant propagation frequency of stalling cells was found in the range of $1.5-2.0 \mathrm{~Hz}$ by simulations and experiments, as can be seen from the detail plot in Fig. 17(a) and Fig. 17(b). When operating at a small opening angle $0.8 \alpha_{o}$, the frequency spectrum in Fig. 17(c) shows no peak at the characteristic rotating stall frequency and instead a comparably minor peak in the very low frequency range at about $0.5 \mathrm{~Hz}$ (equal $f / f_{\Omega}=0.038$ ). In Table 4 , the dominant rotating stall frequencies in the low-frequency range are summarized. The amplitude of the rotating stall frequency is approximately 2.5 times higher than the pressure amplitude of the blade passing frequency for opening angle $1.1 \alpha_{o}$ and approximately 2 times higher at opening angle $\alpha_{o}$. At an opening angle $0.8 \alpha_{o}$, however, the amplitude of the blade passing frequency is 2.5 times higher than the amplitude of the stall frequency. For all opening angles, the peaks of the harmonics at $f / f_{\Omega}=7,14$, 21 and 28 show a considerable correlation between simulation results and experiments. However, the pressure amplitudes at $f$ $/ f_{\Omega}=14$ and $f / f_{\Omega}=28$ are underestimated by CFD.

Table 4 Comparison of normalized stall frequencies $f / f_{\Omega}$ between simulation and experiments for different guide vane openings.

\begin{tabular}{llll}
\hline & $1.1 \alpha_{o}$ & $\alpha_{o}$ & $0.8 \alpha_{o}$ \\
\hline EXP & 0.125 & 0.113 & 0.038 \\
SIM & 0.120 & 0.132 & 0.041 \\
\hline
\end{tabular}

Figure 18 shows the according time curves of the stay vane channel flows. The time curves in Fig. 18(a) and Fig. 18(b) show a significant periodicity where the flow fluctuation is more pronounced at guide vane opening angle of $1.1 \alpha_{o}$. Figure 18(c) presents the flow behavior in the stay vane channel at a smaller guide vane opening $0.8 \alpha_{o}$. Besides a flow fluctuation at $30 \%$ of the impeller rotational speed, the very slowly moving disturbance at about $0.5 \mathrm{~Hz}$ can be seen.

In Fig. 19 the correlation between the upper and lower flow rate for different guide vane openings under the same flow conditions is shown. Due to significant periodic flow fluctuations in both upper and lower signal curves, a high correlation is obtained for all three guide vane openings. In order to better visualize the stalled flow behavior, the circumferential variation of the meridional velocity in the stay vane channel 1 to 20 is shown in Fig. 20 for two different times at opening $\alpha_{o}$. For this purpose, a cylindrical sampling line is defined at $50 \%$ of the stay vane chord length and $50 \%$ in spanwise direction.

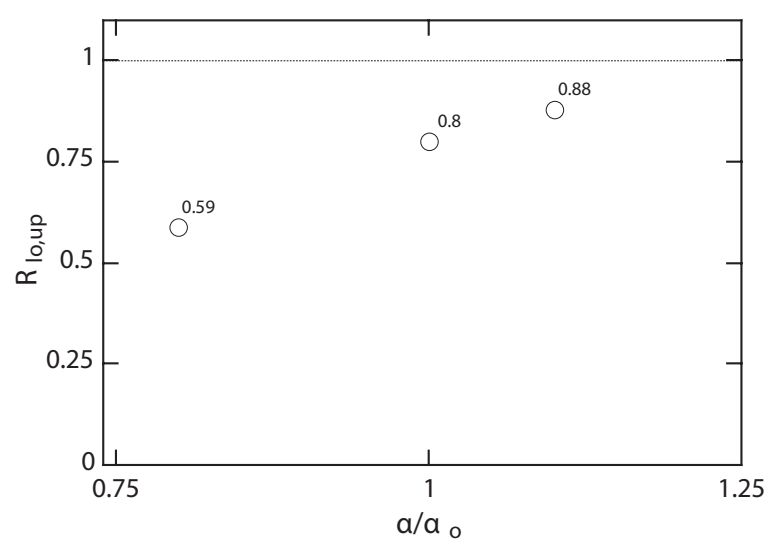

Fig. 19 Cross-correlation between upper and lower flow signal for different guide vane openings $\alpha$.

The non-uniform velocity distribution is plotted for time $t$ and for the time after one quarter revolution of the stalled cells $t+f_{R S} / m$. This comparison reflects the severe periodic flow variation in terms of four dominant jets with adjacent blocked cells in pitchwise direction for $\theta=0, \theta=\pi / 2, \theta=\pi$ and $\theta=3 \pi / 2$.

Thus, four stalled cells $m=4$ can be clearly identified.

To show the blockage and discharge flow in the distributor, iso-contours of the entropy $S$ and the velocity magnitude $C$ are introduced. As suggested in [14], the local generation rate of entropy of a isothermal and incompressible fluid $\dot{S}=\dot{S}_{D}+\dot{S}^{\prime}$, $\dot{S}$ can be divided into the part due to mean flow gradients 


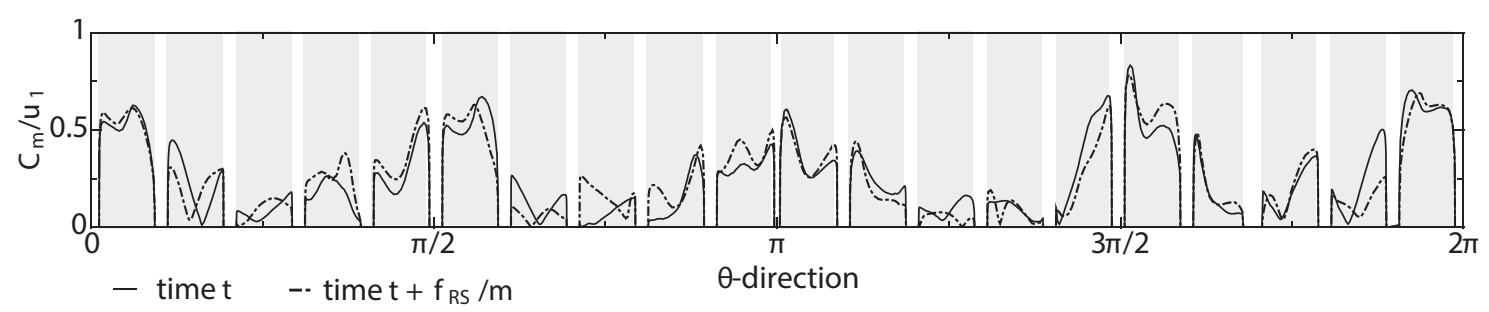

Fig. 20 Velocity $C_{m}$ in the stay vane channel at $Q_{E D} / Q_{E D n}=0.74$ and opening angle $\alpha_{o}$ for two different time instants.

$$
\begin{aligned}
\dot{S}_{D}=\frac{\mu}{\bar{T}}\left[2\left(\frac{\partial C_{x}}{\partial x}\right)^{2}+2\left(\frac{\partial C_{y}}{\partial y}\right)^{2}+2\left(\frac{\partial C_{z}}{\partial z}\right)^{2}+\right. & \\
& \left.\left(\frac{\partial C_{x}}{\partial y}+\frac{\partial C_{y}}{\partial x}\right)^{2}+\left(\frac{\partial C_{x}}{\partial z}+\frac{\partial C_{z}}{\partial x}\right)^{2}+\left(\frac{\partial C_{z}}{\partial y}+\frac{\partial C_{y}}{\partial z}\right)^{2}\right]
\end{aligned}
$$

and the part resulting from dissipation in the turbulent shear of separating flow [15]

$$
\dot{S}^{\prime}=\frac{\rho \beta^{*} \omega k}{\bar{T}}
$$

where $\bar{T}$ is the mean fluid temperature and $\beta^{*}=0.09$ a model coefficient of the $k-\omega$ model. In Fig. 21, iso-contours of the maximum entropy and the normalized velocity magnitude $C / u_{1}=0.45$ are shown at $50 \%$ span of the stay vanes for different guide vane openings $0.8 \alpha_{o}, \alpha_{o}$ and $1.1 \alpha_{o}$ during fully developed stall regime. For angles $1.1 \alpha_{o}$ and $\alpha_{o}$, four notable regions of strong dissipation are visible that fully block the channel. These cells of high entropy mainly appear at the stay vane channel inlet and result in a strong stay vane channel flow upstream in direction of the impeller rotation. At smaller guide vane opening angle $0.8 \alpha_{o}$, the flow pattern in the distributor exhibits 5-6 non-uniformly distributed stall cells which cannot be accurately determined.

By applying the relationship $f_{R S}=f / m$, the fundamental frequency of the rotating stall $f_{R S}=0.125 f_{\Omega} / 4$ is found for opening angle $1.1 \alpha_{o}$, which is equal $3.12 \%$ of the impeller rotational speed. For opening $\alpha_{o}$, the fundamental frequency $f_{R S}=0.113 f_{\Omega} / 4$ is obtained, which is equal to a propagation speed of $2.82 \%$ of the impeller rotational speed. For guide vane position $0.8 \alpha_{o}$, the frequency $f_{R S}$ is not computed as the number of stalling cells cannot be fully determined from the plots. However, this dominant sub-synchronous frequency appears to modulate the blade passing frequency $7 f_{\Omega}=93.3 \mathrm{~Hz}$, resulting in remarkable side bands.

\section{Conclusions}

Unsteady flow simulations and experimental investigations have been conducted to address flow characteristics and unsteady flow phenomena in the stay vane channel.

Analysis of the stay vane channel flow showed uneven velocity profiles across the stay vane channel height during off-design operation. Close to the design point, the bulk velocity in the stay vane channel was found to be deflected towards the shroud where during deeper part-load operation the opposite was observed. Consequently, CFD and data from experiment have shown a slight downward velocity component in spanwise direction during part-load operation. This downward directed flow behavior has been observed not only near the shroud-side wall, but also near the hub-side wall.

Although a rather coarse computational mesh was used, simulations were able to determine the low-frequency rotating stall observed in the experiment. Due to a large number of simulated runner revolutions and local mesh refinement, structure and propagation of rotating stall phenomenon in the distributor have been captured by CFD.

Only $20 \%$ below the design flow, characteristic peaks between $1.5-1.8 \mathrm{~Hz}$ were encountered for an optimum guide vane opening which is in agreement with the experiment. Four stalling cells traveling at $2.8-3.1 \%$ of the impeller rotary frequency were observed when analyzing the flow field in the distributor. Simulations have also shown the influence of the guide vane position on the onset of rotating stall in the distributor. Caused by an unfavorable incidence angle at the guide vane inlet edge, these dominant rotating stall frequencies disappeared when reducing the guide vane opening by $17 \%$. Instead, the appearance of a minor peak in the very low frequency range

\begin{tabular}{|c|c|c|}
\hline$A$ & {$[\mathrm{~Pa}]$} & pressure amplitude \\
\hline C & {$\left[\mathrm{m} \mathrm{s}^{-1}\right]$} & absolute fluid velocity \\
\hline$f$ & {$[\mathrm{~Hz}]$} & frequency \\
\hline$f_{\Omega}$ & {$[\mathrm{Hz}]$} & impeller rotation frequency \\
\hline$H$ & {$[\mathrm{~m}]$} & head \\
\hline$h$ & {$[-]$} & grid size \\
\hline$J$ & {$[-]$} & $\begin{array}{l}\text { total number of faces in } \\
\text { computational domain }\end{array}$ \\
\hline$k$ & {$[-]$} & blending factor \\
\hline$N$ & {$[-]$} & number of cells \\
\hline$n$ & {$[\mathrm{rpm}]$} & impeller speed \\
\hline$Q$ & {$\left[\mathrm{~m}^{3} \mathrm{~s}^{-1}\right]$} & flow rate \\
\hline$Q_{E D}$ & {$[-]$} & discharge factor \\
\hline$q_{u p}$ & {$\left[\mathrm{~m}^{3} \mathrm{~s}^{-1}\right]$} & flow rate upper channel zone \\
\hline
\end{tabular}
at $0.5 \mathrm{~Hz}$ has been revealed by CFD and experiments.

\section{Nomenclature}



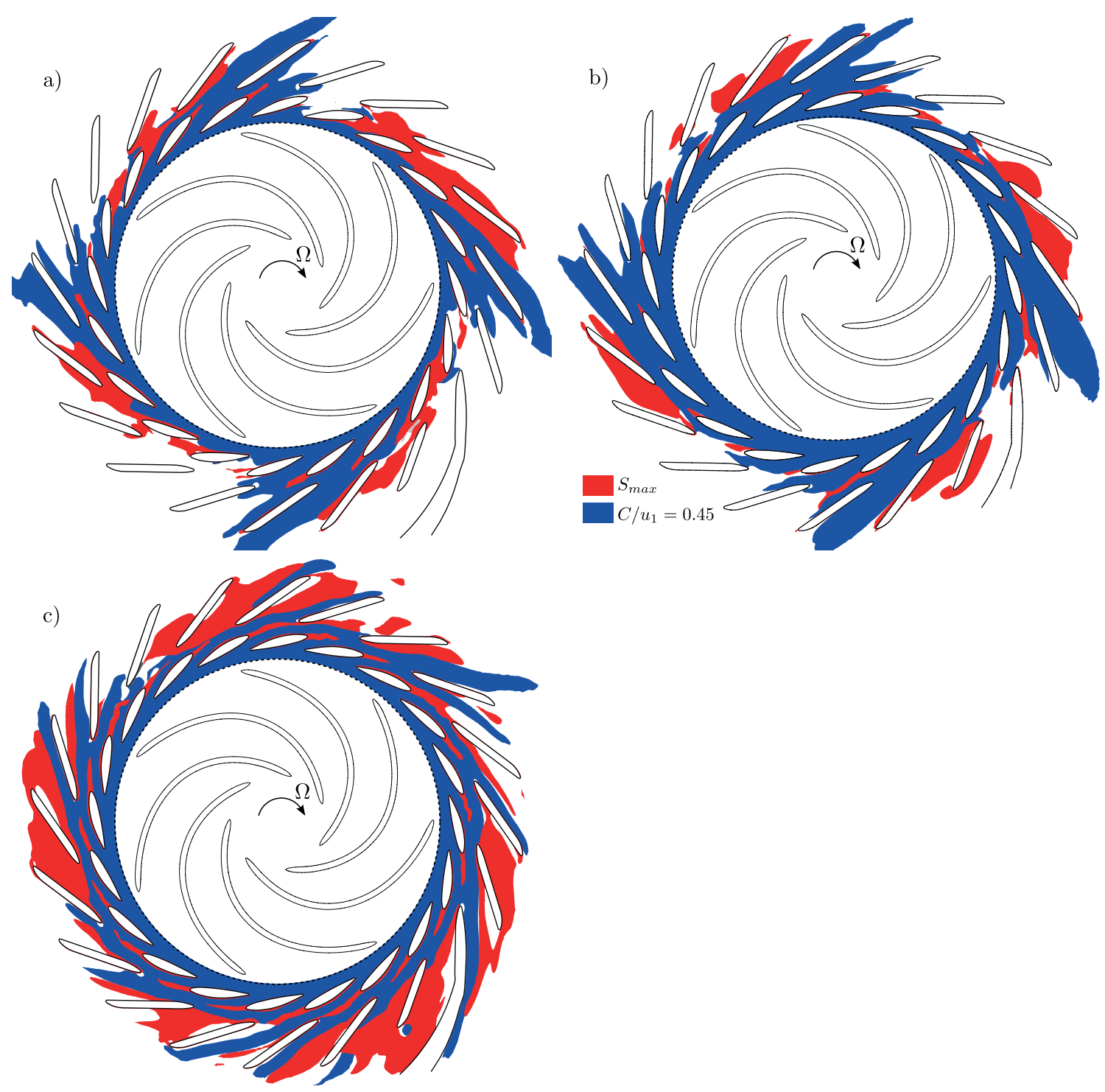

Fig. 21 Iso-surfaces of instantaneous velocity magnitude $C$ and entropy $S$ at $Q_{E D} / Q_{E D n}=0.74$ : a) $\alpha=1.1 \alpha_{o}$, b) $\alpha=\alpha_{o}$, c) $\alpha=0.8 \alpha_{o}$.

\begin{tabular}{|c|c|c|}
\hline$q_{l o}$ & {$\left[\mathrm{~m}^{3} \mathrm{~s}^{-1}\right]$} & flow rate lower channel zone \\
\hline$r$ & {$[-]$} & grid refinement ratio \\
\hline$R_{q_{l o} q_{u p}}$ & {$[-]$} & cross-correlation \\
\hline$S$ & {$\left[\mathrm{~J} \mathrm{~K}^{-1}\right]$} & $\begin{array}{l}\text { between } q_{u p} \text { and } q_{l o} \\
\text { entropy }\end{array}$ \\
\hline $\bar{T}$ & {$[\mathrm{~K}]$} & mean fluid temperature \\
\hline$y^{+}$ & {$[-]$} & dimensionless wall distance \\
\hline$\alpha_{o}$ & {$[\circ]$} & guide vane opening angle \\
\hline$\beta^{*}$ & {$[-]$} & model coefficient \\
\hline$\varepsilon_{h}$ & {$[-]$} & discretization error \\
\hline$\rho$ & {$\left[\mathrm{kg} \mathrm{m}^{-3}\right]$} & density of water \\
\hline$\Phi$ & {$\left[\mathrm{m}^{3} \mathrm{~s}^{-1}\right]$} & face flux \\
\hline$\phi$ & {$[-]$} & scalar or vector quantity \\
\hline$\psi$ & {$[-]$} & blending factor \\
\hline$\psi(r)$ & {$[-]$} & flux limiter \\
\hline$\Omega$ & {$\left[\mathrm{s}^{-1}\right]$} & impeller angular speed \\
\hline
\end{tabular}

\section{References}

[1] Mesquita, A. L., Ciocan, G. D. "Experimental analysis of the flow between stay and guide vanes of a pump-turbine in pumping mode." Journal of the Brazilian Society of Mechanical Sciences. 21(4), pp. 580-588. 1999.

[2] Berten, S., Dupont, P., Fabre, L., Kayal, M., Avellan, F., Farhat. M. "Experimental investigation of flow instabilities and rotating stall in a high-energy centrifugal pump stage." In: Proceedings of ASME 2009 Fluids Engineering Division Summer Meeting. FEDSM2009. Vall, Colorado, USA, Aug. 2-5, 2009. p. 9.

[3] Anciger, D., Jung, A., Aschenbrenner. T. "Prediction of rotating stall and cavitation inception in pump turbines." In: IOP Conference Series: Earth and Environmental Science. 12(1), 012013, 2010. https://doi.org/10.1088/1755-1315/12/1/012013

[4] Braun, O. "Part load flow in radial centrifugal pumps." PhD thesis, École Polytechnique Fédérale de Lausanne, Thése No.: 4422. 2009.

[5] Xia, L. S., Cheng, Y. G., Zhang, X. X., Yang, J. D. "Numerical analysis of rotating stall instabilities of a pump-turbine in pump mode." In: IOP Conference Series: Earth and Environmental Science. 22, 032020. 2014. https://doi.org/10.1088/1755-1315/22/3/032020 
[6] Zhang, Z. "Rotating stall mechanism and stability control in the pump flows." In: IOP Conference Series: Earth and Environmental Science. 12(1), 012010. 2010.

https://doi.org/10.1088/1755-1315/12/1/012010

[7] Erne, S., Edinger, G., Bauer, C. "Numerical study of the stay vane channel-flow in a reversible pump turbine at off-design conditions." In: Conference on Modelling Fluid Flow (CMFF'15). The 16th International Conference on Fluid Flow Technologies, Budapest, Hungary, Sept. 1-4, 2015. pp. 1-8.

[8] Edinger G. "Experimentelle Untersuchungen zum tiefen Teillastbetrieb von Pumpturbinen." PhD thesis, Vienna University of Technology, 2014. (in German)

[9] ANSYS Inc. ICEM CFD 13.0, Manual, September 2010.

[10] "Procedure for estimation and reporting of uncertainty due to discretization in CFD applications." Journal of Fluids Engineering. 130(7), 078001-078001-4. 2008.

https://doi.org/10.1115/1.2960953
[11] Phillips, T. S., Roy, C. J. "Richardson extrapolation-based discretization uncertainty estimation for computational fluid dynamics." Journal of Fluids Engineering. 136(12), 121401. 2014. https://doi.org/10.1115/1.4027353

[12] Jasak, H. "Error analysis and estimation for the finite volume method with applications to fluid flows." PhD thesis, Imperial College London (University of London), 1996.

[13] Hunt, J. C. R., Wray, A. A., Moin, P. "Eddies, streams, and convergence zones in turbulent flows." In: Proceedings of the 1988 Summer Program. Center for Turbolence Research. pp. 193-208. 1988.

[14] Herwig, H., Kautz, Ch. H. "Technische Thermodynamik." Pearson Studium, 2007. (in German)

[15] Kock, F., Herwig, H. "Local entropy production in turbulent shear flows: a high-Reynolds number model with wall functions." International Journal of Heat and Mass Transfer. 47(10-11), pp. 2205-2215. 2004. https://doi.org/10.1016/j.ijheatmasstransfer.2003.11.025 